\title{
Dimensions of cooperative spectrum sharing: Rights and enforcement
}

\author{
Liu Cui \\ School of Information Sciences \\ University of Pittsburgh \\ Pittsburgh, Pennsylvania 15260 \\ Email: lic49@pitt.edu
}

\author{
Marcela M. Gomez \\ School of Information Sciences \\ University of Pittsburgh \\ Pittsburgh, Pennsylvania 15260 \\ Email: mmg62@pitt.edu
}

\author{
Martin B.H. Weiss \\ (Corresponding Author) \\ School of Information Sciences \\ University of Pittsburgh \\ Pittsburgh, Pennsylvania 15260 \\ Email: mbw@pitt.edu
}

\begin{abstract}
Sharing of radio spectrum requires a careful and nuanced understanding of the rights of incumbents and spectrum entrants. In addition, the dynamics of stakeholders can be understood by examining how various rights are arranged (and rearranged) among them. Importantly, understanding the rights and their distribution is the predicate to developing rational and useful enforcement approaches.

In this paper, we show that spectrum sharing involves a rearrangement of the rights associated with radio spectrum among stakeholders. We show how this rearrangement of rights implies the definition of new bundles of rights, appropriate to each particular sharing scenario. We discover these rights - and their (re)arrangement) - by examining several cases of spectrum use. We begin with the rights associated with exclusive use and proceed to consider rights arrangement in commons and different spectrum sharing configurations. Further, in the case of commons, we explicitly examine how governance of commons can affect the rights distribution in spectrum. In each case, the bundles of rights associated with each stakeholder changes.

New bundles of rights have consequences, not only on the behavior of spectrum users but also on the enforcement process. Our examination of the bundles of rights shows that each rearrangement results in different approaches to enforcement. We demonstrate this by revisiting enforcement in the cases we examine.
\end{abstract}

\section{INTRODUCTION \& BACKGROUND}

Spectrum sharing inevitably leads to interference. This means that both spectrum incumbents and entrants will feel the need to develop enforcement mechanisms to manage interference [1]. Rational choices about enforcement approaches and costs require analysis of rights, objectives, precision, etc. [2] as well as metaphor [3]. Further, what is in question is a possibly complex bundle of rights [4].

We have informally observed that spectrum sharing does not fall neatly into one or the other of the cooperativenon-cooperative sharing dichotomy typically offered in the literature (see, for example, [5], [6]). This is consistent with number of studies of radio sharing and the resolution of interference [4], [7], [8], even though these authors have different theoretical views. In each of the examined cases, spectrum sharing was resolved through private action rather than through legal means.

Authors such as Demsetz [9] and Coase [10] would argue that the rights to use and to interfere emerge from either de facto or de jure property rights and would, in the absence of transaction costs, be acquired by the organization or use that can put those rights to the highest social use. Smith [2] argues that various forms of governance are possible on the continuum between exclusion and commons.

To better understand what rights are in question and how they are bundled and (ultimately) enforced, we examine two general cases of spectrum sharing. First, we consider usage rights in the ISM band and their distribution via examples on three different scenarios: a US university campus, airports and a particular geographic area. In the second case, we contrast the dynamics of the voluntary sharing in WiFi with the de jure sharing being proposed by the US National Telecommunications and Information Agency (NTIA); in particular, we consider sharing in the $1695-1710$ and $3550-3650 \mathrm{MHz}$ bands.

\section{Spectrum Related Rights}

Property rights associated with electromagnetic spectrum were first proposed by Coase [11], though it took many years for these notions to be incorporated, even partially, into government policy. In short, Coase pointed out that the most efficient way to assign spectrum is to give it to those users who value it the most through property-like rights and secondary markets. Fishman [12] argues that property rights are in fact a bundle of specific rights: "[property rights] imply the ability to buy; hold; use; sell; dispose of, in whole or in part; or otherwise determine the status of an identifiable, separable and discrete object, right or privilege."

Faulhaber and Farber [13] discuss the idea of constructing an appropriate bundle of rights to define property in spectrum. The starting point for this is directly related to (and limited by) the technical requirements affecting the exclusive usage rights. The definition of spectrum rights begins with the exclusive usage spectrum rights model. Toward that end, De Vany et. al. [14] proposed a multidimensional set of rights called TAS, which implies that "the owner of the TAS-based rights would have the exclusive right to produce electromagnetic waves for a specified period of time (T), over a specified geographic area (A), and in a specified range of frequency (S)." TAS is said to define an electrospace. Matheson and Morris [15] expand this to a seven dimensional model, which includes frequency, time, three dimensions of location (latitude, longitude, and 
elevation) and two possible directions of arrival (azimuth and elevation angles) and apply it in an attempt to define an exclusive rights region. It is important to note that interference and noise are stochastic processes, which vary with time and location so that exclusion may not be complete. Thus, even if spectrum rights are defined through one of these electrospace models, unexpected interference and noise cannot be prevented nor can the quality of the resource be guaranteed [16].

From a legal perspective, the definition of spectrum rights starts with exclusive usage rights (in the US) because Section 303(f) of the Communication Act of 1934 requires the FCC to prevent interference between stations. Because of this, the FCC adopted the "command-and-control" approach to spectrum management in hopes of making spectrum usage more predictable. In the command-and-control approach, the spectrum license bundles a group of rights in an electrospace, including:

- rights to establish infrastructure

- rights to transmit

- rights to receive without interference

- rights to provide a particular type of services

This means that only licensees have the right to construct the infrastructure, transmit in the frequency bands and provide services as determined in the license. Other users have no rights to do so in the same electrospace. Note that the right to receive is different than the right to receive without interference. For example, receivers exist for NOAA's METSAT service (discussed later in this paper) that have the right to receive, but are not guaranteed to receive without interference. Similarly, users of automotive radar detectors have the right to receive radar signals in most U.S. states, but this is not guaranteed to be interference free, nor is it universal (e.g., Virginia has removed this right from its geographic territory). Finally, AM broadcast receivers may receive signals from very distant transmitters at night, but reception without interference is not guaranteed for these propagation modes.

As demand for spectrum access has increased, it has become increasingly difficult to identify new electrospace for both new entrants and incumbents due, in part, to the exclusive usage paradigm. As a consequence, the notion of spectrum sharing has been introduced in spectrum management. Spectrum sharing breaks and rearranges the existing spectrum rights bundle, and reassigns rights to different parties. For instance, the spectrum license no longer bundles spectrum rights with the right to establish infrastructure, right to transmit, right to provide services, etc. In other words, licensees are not the only party to operate in that electrospace. Unlicensed users or secondary users (depending on different spectrum models) also have the right to build infrastructure, transmit, and provide services. Furthermore, with the liberalization of spectrum, unlicensed and secondary users may not be limited to provide services specific to the spectrum license (i.e., secondary users in TV bands are free to provide broadband services in the White Spaces).

Spectrum virtualization, which is an emerging approach for spectrum management and usage, promises to rearrange spectrum rights even further [17], [18]. One of the ultimate goals for spectrum virtualization is for spectrum users to utilize any idle frequency and transmit signals using the most appropriate technologies and devices. That means spectrum users may share spectrum, devices, and their devices are programmable to support different types of services. In this case, there may emerge infrastructure providers that transmit signals, spectrum licensees that lease spectrum to other users, service providers that offer innovative applications and deal with customer relationships, etc.

Notably, with the implementation of spectrum sharing, other types of spectrum rights arise. First, we can identify the right to underlay, which may be granted to secondary users in order to allow devices to operate under the primary users' noise floor. Ultra Wide Band (UWB) is an example in spectrum underlay. A second type of right would be the right to overlay, which permits secondary users to transmit in licensed bands above the noise floor, presumably without interfering with the license holder. These two types of rights define the operation and also enforcement requirements in these new modes of spectrum use.

It may be useful to consider other rights as well. For example, by focussing on the spectrum operating environment rather than on user protection, De Vries and Sieh propose reception rights, comprised of probabilistic reception protections and transmission permissions to define spectrum operation rights [19]. Further, Weiss and Cui propose interference rights [20]. The interference rights explicitly allow secondary users to interfere with existing services offered by a primary user to a certain level. Licensees can write interference rights under their license, which can be traded, combined, or exchanged with other users. Ofcom developed the notion of spectrum usage rights, which specify the emissions that a license holder may transmit in neighboring bands or locations, instead of specifying a transmission power cap for each transmitter [21].

In the above analysis, we only consider rights that are directly related to spectrum operations. The rights regime gets even more complicated when we consider commons and Coasian negotiation. In spectrum commons, like the WiFi band, a particular asset is made available for the use of all, with common restrictions that govern the corresponding usage restrictions for all [13]. Thus, all spectrum users have equal rights in terms of spectrum usage and are not entitled to protection from interference. However, when spectrum users get involved in disputes derived from spectrum usage and interference, rights such as local authority and land ownership may influence the rights that are directly related to spectrum operations.

When spectrum sharing happens under Coasian negotiation, rights associated with spectrum utilization are totally or partially exchanged among parties. According to Demsetz, "A bundle of rights often attaches to a physical commodity or service, but it is the value of the rights that determines the value of what is exchanged [9]." So, the rights that have been exchanged determine the spectrum trading price.

In addition to framing property rights with a specific 
spectrum sharing model, Faulhaber and Farber [13] add a further notion of economic efficiency to the definition of the bundle of rights. These authors state that for the bundle to be meaningful,"the scope of property must be economically viable in order to avoid the tragedy of the anticommons. But it must not be so large as to encourage market dominance." In other words, even if an initial perfect definition of the bundle of rights is not necessary, it should be carefully performed so that it allows for future transactions and private contracts to remedy any preliminary mistakes.

The discussion above suggests that this bundle of rights is both richer than previously thought and dynamic. Figure 1 is a collection of the rights identified here and how they change under different spectrum management regimes; we make no claim that it is complete.

An important factor that needs to be addressed in the definition of this bundle of rights (or any property rights regime) is how well it permits these rights to evolve with technology [13]. Following this idea and our previous discussion, there are many circumstances that could be used to illustrate different compositions and complexities of bundles of rights. Our main purpose in this paper is to portray how spectrum rights are restructured in spectrum sharing scenarios and how this affects enforcement. In this context, we present examples of spectrum sharing in the ISM band (presumably under a spectrum commons model) and cooperative spectrum sharing which includes de jure sharing and private negotiation.

After analyzing spectrum rights in each of our selected scenarios, we shall consider how the particulars of each situation impact the development of enforcement mechanisms and strategies. Intuition might tell us that a general enforcement framework would not be suitable or not likely to be developed. Similarities will exist; however, each particular situation will rely on its own enforcement guidelines.

\section{COMMONS AND GOVERnANCE IN THE ISM BANDS}

In this paper, we focus on sharing in the ISM bands, given that it is commercially popular and there is a large literature on this topic. Nonetheless, we would like to start our discussion with the (historically) first approach to this shared use of spectrum, namely Amateur Radio Service (ARS). This particular case results rather interesting as it appears as a "hybrid" of licensed use and the commons. Users who are interested in accessing one of the twenty-six bands allocated for amateur radio need to obtain a license from the FCC (i.e., they need to pass an exam to prove their eligibility before they are granted a license). Once licensed, users need to coordinate their access to the spectrum with others by selecting the appropriate transmitting channels given that frequencies are not assigned for exclusive use of any station. Additionally, through cooperation, users need to ensure efficient spectrum usage. ${ }^{1}$ This type of spectrum utilization may be construed as a type of "private commons" because membership is controlled through the operator license, amateur radios must not cause

\footnotetext{
${ }^{1}$ See http://www.ecfr.gov Title 47, Part 97 on Amateur Radio Service
}

harmful interference to other radio communications or signals, and they must accept interference from other licensed users. In other words, they are not entitled to interference protection, just as is the case of the ISM bands. In situations when harmful interference with licensed users is detected and cannot be prevented, amateur radio transmissions are restricted to specific time slots when this harm is nullified or at least minimized. In summary, users of the amateur radio service will have the right to deploy the infrastructure, the right to transmit, the right to receive (but not the right to receive without interference). Note that no license is required for the right to receive.

A less restrictive commons can be found in the various "Personal Radio Services" (e.g., Citizen's Band) authorized by the FCC ${ }^{2}$. The PRSs generally bundle licenses with equipment that complies with the technical regulations and require users to work out interference amongst themselves; of course, the FCC is the ultimate arbiter of any disputes. These rights are very similar to the rights users have in the ISM bands, which will be illustrated below.

$\mathrm{WiFi}$ is one of the most popular technologies to use the commons form of spectrum management. WiFi uses a link layer protocol that embodies a spectrum etiquette to facilitate fairness in sharing [22]. In this paper, we are interested in a different aspect of $\mathrm{WiFi}$ and spectrum sharing: that of a de facto hierarchy of rights that can be analyzed through the lens of Coase and Smith. To illustrate the existence of these hierarchies of rights, we point out several examples in different environments and the objectives that drive their formulation.

\section{A. Spectrum sharing in University campuses}

Although the ISM bands operate on a license free basis, institutions often assert rights connected with these bands. Such assertions may or may not be justified unter the FCC's OTARD (Over the Air Devices) rules ${ }^{3}$. At the University of Pittsburgh, the central computing and networking unit does not permit the unauthorized use of these bands. Under the Wireless Network Standards, it says

In order to prevent problems caused by radio interference, to ensure the integrity of University resources, and to ensure the widest availability of reliable wireless networking services, the University shall remain the sole owner of all unlicensed spectrums [sic] of radio frequencies available for use on any of its campuses and related properties. ${ }^{4}$

The target of this ban is generally not low power devices, such as those using Bluetooth, but higher power devices such as $\mathrm{WiFi}$ access points. Interviews with engineers and administrators reveal that they wish to control the user experience when they are connected wirelessly to the greatest extent possible, and that they want to ensure that wireless communications are secured according to the standards of the organization. The

\footnotetext{
${ }^{2}$ U.S. Code of Federal Regulations, Chapter 47, Part 95

${ }^{3}$ See 47 C.F.R. $\$ 1.4000$

${ }^{4}$ http://technology.pitt.edu/network-web/responsibilities/wireless-networkstandard.html, downloaded on 4 November 2013
} 


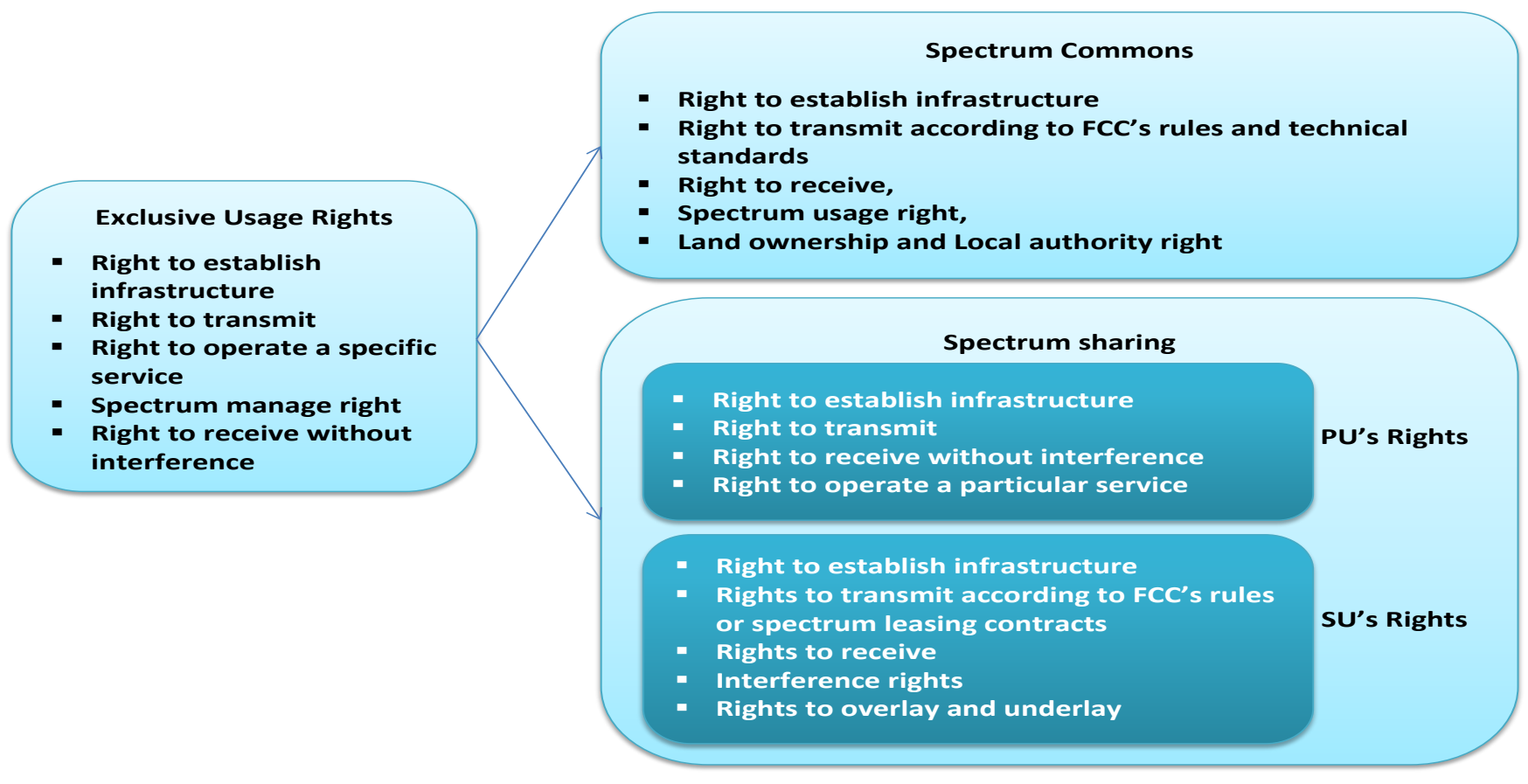

Fig. 1. Bundles of spectrum rights

University of Pittsburgh is not alone in this policy; a brief survey of public and private universities showed that similar policies were widespread.

But university administrators must tread carefully. In 2004, the University of Texas at Dallas tried to restrict students from using personal wireless networks in student residences. UT-Dallas wireless service coverage extended throughout its campus, including students' residences. However, many students living in these residences opted to pay for service with local providers and share it with their room mates via private wireless networks. As mentioned by the University's Executive Director of Information Resources, these private access points were interfering with the use of the university's wireless network, at times even preventing people from signing in to the official network. It was additionally stated that such interference is unfair to other residents, and students who cannot afford to pay for an external internet service should have the right to use the university's network free of charge. UT-Dallas officials modified their position when they learned that the FCC OTARD rules for landlords prohibiting wireless use of their lessees, including the use and installation of wireless access points were unlawful [23]. After this, UTDallas reversed the ban on private wireless use in certain student residences ${ }^{5}$.

\section{B. Dispute between Logan airport and Continental Airlines}

In 2005, Logan International Airport in Boston tried to block Continental Airlines from providing free WiFi service,

\footnotetext{
${ }^{5}$ See http://www.utwatch.org/oldnews/fwst-wifi-9-22-04.html and http://net.educause.edu/ir/library/powerpoint/SWR0548.pps
}

a service which the airport charged a fee of $\$ 7.95$. The arguments provided by the airport included that Continental's WiFi service interfered with other wireless devices and represented a threat to security. Continental rejected this claim and argued that Logan authorities could not legally ban their services since the latter were consistent with FCC regulations [24].

FCC sided with Continental Airlines since WiFi is an unlicensed service, no WiFi operator is entitled to receive protection against harmful interference from other WiFi operations [25]. The FCC cited its established OTARD rules that allow tenants to install and operate their own small antennas under certain circumstances. FCC decided that $\mathrm{WiFi}$ hubs/antennas are also covered under these rules. Consequently, the FCC has ruled that tenants are allowed to install their own $\mathrm{WiFi}$ networks within their own leased spaces ${ }^{6}$.

\section{Resolving Interference among WISPs}

Sandvig [8] provides examples of two cases in which Wireless Internet Service Providers (WISPs) encountered conflicting use of the ISM band. In general, unlicensed bands constitute an appealing option for the deployment of broadband service in areas where it has not been provided yet. These areas are normally small in population and located in rural environments outside of the range of coverage of large telecommunications carriers. It is in this situations that small local service providers make business plans in order to bring broadband services to these unattended areas. Since local service providers cannot afford an exclusive license, at least not to the full extent of their services, they take advantage

\footnotetext{
${ }^{6} \mathrm{http}: / / \mathrm{www} . i b l s . c o m / i n t e r n e t-l a w-n e w s-p o r t a l-v i e w . a s p x ? s=l a t e s t n e w s-$ id $=1632$
} 
of the existing unlicensed spectrum in order to deploy their service infrastructure. A case study presented in [8] shows the possible outcomes of such a situation in a given geographical area.

This example presents Planetree Forest, an area composed of fifty-four small towns, where only dial-up Internet access was available at the time of the case. In response, a firm providing high-speed service, TownNet, was deployed using unlicensed spectrum. A second firm, SATNet, which had previously been providing services in adjacent areas, decided to enter then market in Planetree as well, also making use of license-exempt bands. Since both service providers were operating upon the same spectrum in overlapping geographical areas, coordination of spectrum use was needed. At first the two firms negotiated which channels each firm should use in order to avoid interference. As it turned out, the agreement was not always kept; this is not surprising since the firms were competing with each other as well. In the specific case of Planetree, it was not clearly determined what mechanism SATNet was utilizing to interfere with TownNet, but the outcome was that TownNet subscribers had no Internet service, even indoors. The municipal government and other external members intervened with a goal of settling the disputes. Even after the parties reached an agreement on the specific channel TownNet would be allowed to use, SATNet demanded payments for reconfiguring the integrity of their network in order to comply with the new requirements. The dispute between these two service providers came to an end but for entirely different reasons. It turns out that both entities had been providing services with uncertified equipment which was interfering with an adjacent licensed band.

\section{Discussion}

As stated in Section II, the spectrum rights mentioned by prior research mainly consider spectrum related rights. In the unlicensed bands that use commons-based spectrum management, and also in the particular case of amateur radios, spectrum users have equal rights in deploying devices and transmitting as long as they comply with the FCC's rules. However, the three cases above show that these spectrum rights alone do not determine spectrum usage rights. Specifically, although certified devices such as private routers are legally allowed to operate in unlicensed bands, the rights to manage this spectrum when operating in specific environments, such as universities, may be "acquired". In the case of universities, the restrictions are designed to maximize social benefits (at least this is claimed).

It might be expected that condominium owners or apartment dwellers would explicitly coordinate WiFi sharing with each other to maximize net throughput (despite OTARD rules); however, no examples of this could be found. Instead, some end users leave WiFi for cable-based Ethernet when congestion becomes severe, while others use channel scanning software to identify those channels that would interfere least. In still other cases, owner's associations or landlords might "acquire" rights by offering $\mathrm{WiFi}$ service to their tenants at zero price. Such an offering would allow for centralized management/optimization of WiFi for the community of tenants. In the Williamson's framework [26], this could also be considered an example of "hierarchy" (or central coordination) when the transaction costs are too high.

As observed, this bundle of rights in spectrum commons includes the rights to establish infrastructure, the right to transmit and receive according to FCC's rules, the right to transmit and receive as recommend by technical standards, other rights such as land ownership rights and local authorities, etc. From a Coasian point of view, the computing and networking department of the university has acquired the collection of rights associated with the ISM bands (by fiat in this case), since it is more valuable for the university than for individuals and departments.

The limited transmission power cap in the unlicensed ISM bands is meant to keep interference and collisions at an acceptable level. However, these ex ante rules alone cannot provide a harmonized spectrum environment due to the intensive usage of these bands. As Sandvig stated in his paper "when legal constraints are removed, users make their own order and are bound by their own local and differing standards of fairness and propriety." In this case, although ISM bands have legal constraints, they are not enough for efficient usage. Therefore, cooperation among unlicensed users, beyond the rights that are determined by the FCC, are needed for achieving a better QoS.

The IEEE 802.11 group took the first step in mandating devices to sense the carrier before operation ("Listen-beforetalk") in order to reduce interference and collisions. The IEEE 802.11 standard is a technical cooperation among unlicensed users. It harmonizes the spectrum usage environment, ensures fairness and eventually improves system performance [22]. Similar standards include, but are not limited to Bluetooth, Zigbee, etc. The major advantage provided by standards (technical cooperation) is avoiding transaction costs in negotiation. When the transaction cost is zero, unlicensed users may be able to agree on a spectrum sharing etiquette that achieves the highest mutual benefit which is better than technical cooperation. Unfortunately, negotiation is not free and this cost quickly rises as the number of parties increase. In this case, standards provide a simple and cost effective solution.

The shortcoming of standards is that they assume all users are homogeneous. It is true if by "users" we mean different devices. However, it is not true if "users" represent parties that own and provide services with different devices. Moreover, these parties may have hierarchical authorities and may own different rights in certain locations that impact spectrum usage. For instance, the FCC ruled that Continental Airlines had the right to provide $\mathrm{WiFi}$ services in their rented space, not because Logan Airport and Continental Airlines had different spectrum usage rights in that location but due to the land ownership factor. This also applies to the university case. Students have the right to establish private $\mathrm{WiFi}$ in their dorm, since they rent or lease their dorm rooms. Nevertheless, they are not allowed to provide WiFi services in department 
buildings or even in the hallways.

Deciding which party has the right to use the spectrum depending on the ownership of the land does not end the battle. In the third example, neither of the firms owns/leases/rents the land, and both of them provide similar services. Further, electromagnetic waves travel through geographic boundaries. Except in cases where usage is low, local coordination in such situations is unavoidable. Additionally, local authority intervention would be required in case there are problems that coordination alone cannot solve. In this manner, this would represent a manual means of determining the geographic area, timeslots and channels that each company can use for transmitting.

Despite DeVries's advocacy for other metaphors [3], let us use the spatial metaphor of spectrum to help readers better understand the bundle of rights in spectrum commons. Suppose land is mutually owned and every person in the region has the right to hunt, plant, mine, etc. If each right holder (a person in this case) seeks to maximize his right, he will over hunt and it may lead to the "tragedy of commons". When the negotiation cost is zero, every member of the community can agree to curtail the rate at which they hunt. However, the cost of reaching such an agreement is not zero. Hence, a standard will be deployed and determine the portion of land over which each person can hunt. This standard may not necessarily lead to the optimum solution to the entire community since some of the families may not hunt and others' living may fully rely on hunting. As a result, the community may choose to "govern" these usage rights [2]. Families that rely on hunting may get a larger quota on hunting while surrendering other rights such as planting and mining. Furthermore, this local authority would play an important role in enforcement [9].

\section{CoOperative Sharing}

Compared with commons, cooperative sharing implies hierarchical rights among spectrum users. Primary users have higher priority in using the frequency and secondary users coordinate with primary users in order to operate in the band. Depending on the motivation, there are two types of cooperative sharing, de jure cooperative sharing and private negotiation.

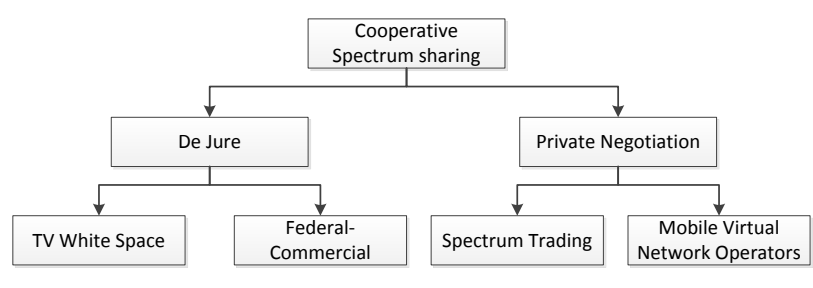

Fig. 2. Cooperative Sharing.

\section{A. De Jure cooperative sharing}

De jure cooperative sharing describes situations of mandated sharing. We will examine two cases of this kind of sharing: TV white space (TVWS) and commercial-federal spectrum sharing. In this case, regulators (notably the FCC and the NTIA) require TV license holders and federal users (such as radar) to share radio spectrum with commercial users. Secondary users do not need to pay for using the spectrum, but they have to follow rules determined by regulators and primary users.

1) TV White Space: In 2008, the FCC released the Second Report and Order to allow unlicensed devices to transmit in the broadcast television spectrum at locations where licensed services are absent. The difference between TVWS and ISM bands is that unlicensed users in TVWS are required to cooperate with primary users first and then share with each other. That is, the secondary user rights (in general) are subordinate to the primary users, but not to other secondary users.

The key requirements for secondary users in the TVWS include: (1) all devices (except personal/portable devices operating in client mode), must have geolocation capabilities and access the database to obtain a list of the permitted channels before transmission; (2) devices that do not have geolocation capabilities and cannot access the database must have the capability to sense TV broadcasting and wireless microphone signals, at levels as low as $-114 \mathrm{dBm}$, and they are subject to lower transmission power limit; (3) all devices must provide identifying information to the database for enforcement purposes, and they are subject to equipment certification by the FCC Laboratory before implementation. The power limit for a $6 \mathrm{MHz}$ channel is: fixed $30 \mathrm{dBm}$ (1 Watt); personal/portable $16 \mathrm{dBm}(40 \mathrm{dW})$; sensing only $17 \mathrm{dBm}(50 \mathrm{~mW})$; all other personal/portable $20 \mathrm{dBm}(100 \mathrm{~mW})$.

TV stations are not the only primary users in TVWS, microphone users are also primary users of this same band. Due to the nomadic usage of microphone and its low transmission power, the TVWS database requires them to register on the database before operation in order to get interference protection.

2) Federal-Commercial spectrum sharing: Sharing between the government incumbents and commercial users is one of the key forms of spectrum sharing recommended by the NTIA and the FCC. The target frequency bands include 1695$1710 \mathrm{MHz}, 1775-1780 \mathrm{MHz}, 3500-3650 \mathrm{MHz}, 4200-4220$ $\mathrm{MHz}$, and $4380-4400 \mathrm{MHz}$. In these bands, primary users' applications can be fixed, portable, or mobile. We provide two demonstrative examples in this paper: $1695-1710 \mathrm{MHz}$ and 3500-3650 MHz, which are drawn from [27].

The $15 \mathrm{MHz}$ available for sharing in the $1695-1710 \mathrm{MHz}$ band have as a primary user the National Oceanic and Atmospheric Administration (NOAA) wich is in charge of weather satellite receive earth stations (Meteorological-Satellite). The target secondary users for this particular case are commercial LTE operators who will be using this band for uplink communications from users' handsets to base stations.

The second example in federal-commercial sharing is found in the $3550-3650 \mathrm{MHz}$ band, which is used by the Department of Defense (DoD) radar systems with installations on land, ships and aircrafts. The secondary users are envisioned as 
small cell systems such as femtocells, picocells or additional methods that work as extensions of macrocell systems. The behavior of the primary users in this case is harder to predict than that of the previous example. In several cases, radars are used for military purposes, thus their spectrum usage characteristics are not disclosed; in other situations, radars are used for emergency systems and thus need a higher degree of spectrum availability and protection from interference. A multi-tiered shared access model is proposed for this band. In this manner, it would be managed by an Spectrum Access System (SAS). This method aims at deploying sufficient interference protection mechanisms for the incumbents in the form of "access tiers" and, consequently, exclusion and protection zones that would limit the access of secondary users to the spectrum to a level that would minimize harm to the incumbents' transmissions.

\section{B. Private negotiation}

In private negotiation, primary and secondary users negotiate spectrum sharing etiquette, in terms of leasing price, location, coverage, transmission power or interference level, frequency, operation duration, etc. Negotiation happens in private markets with or without brokers. Secondary users will obtain operation flexibility at the expense of a certain spectrum leasing price.

1) Spectrum Trading: The FCC released the first Report and Order and Further Notice of Proposed Rulemaking to facilitate spectrum access though the use of spectrum leasing agreement in 2003. It allows primary users to lease some or all of the spectrum usage rights associated with their licenses to third parties. These leasing agreements need to be submitted to the FCC at least 10 or 21 days (depending on the leasing duration) prior to their effective date. The second Report and Order provides immediate processing, such as overnight approval, for certain qualifying spectrum leasing arrangements.

According to the FCC's definition, there are two types of spectrum leasing arrangements: spectrum manager lease and de facto transfer lease. Under the former option, both de jure and de facto control over the leased spectrum are retained by licensees during the leasing period. In the latter option, lesees obtain the de facto control of the leased spectrum while primary users keep the de jure control over it. In both cases, spectrum leasing is further divided into two classes: a short-term lease, limited to one year; and a long-term lease lasting more than one year. Consequently, spectrum entrants can either follow a sharing etiquette determined by primary users or define their own sharing etiquette, based on the leasing arrangements.

2) Mobile Virtual Network Operators: ITU defined Mobile Virtual Network Operators (MVNOs) as operators that offer mobile services to end users without a governmental license. Indeed, MVNOs have access to radio elements of one or more mobile operators in order to offer services to subscribers. These radio elements include radio transmission links, control and mobility management functions that locate and deliver services to end users. MVNOs accounted for $7 \%$ of subscribers in Western Europe and North America in 2003, and this number increased to over 9\% at the end of June $2009^{7}$.

Unlike other spectrum sharing frameworks, MVNOs do not directly operate on the spectrum resource. They rely on Mobile Network Operators (MNOs)'s base stations to transmit and receive wireless signals. There are several types of MVNOs, depending on their infrastructure and agreements. A MVNO can establish everything except radio access and transmission, or it may only focus on marketing and branding. The former type is capable of handling network routing and may have roaming agreements with other MNOs. They are able to produce and distribute voice and data traffic, as well as SMS and MMS messages. The latter is only a wholesaler and distributor of voice and data traffic.

MVNO is an option for wireless service providers to enter into the market in a cooperative way. The major advantage of MVNOs is mainly derived from the low barrier for entering the wireless service industry. They do not need to take part in the time-consuming spectrum licensing procedures nor spend a tremendous amount of money on infrastructure. However, the main disadvantage also stems from this merit. This type of sharing requires the radio access technology, adopted by spectrum entrants, to be compatible with the existing primary users' infrastructure. One further constraint that may appear agreement-wise relies on the fact that primary users may not be interested in enforcement in MVNO since they control the traffic; however, MVNOs may want to ensure the fulfillment of agreements.

\section{Discussion}

1) De jure vs. Private negotiation: De jure and private negotiation has been studied in [28]. In our case, we consider the differences in the incentive for sharing. TVWS and federalcommercial sharing are mandated by regulators. It is generally accepted that spectrum sharing mechanisms will increase overall spectrum utilization; nevertheless, this does not necessarily imply that the incumbents' utility is improved, especially for de jure sharing. In private negotiation, incumbents only share spectrum with secondary users when it is profitable to do so. They may even enhance their own infrastructure and compliant technologies in order to increase the amount of leasable spectrum. This is not necessarily the case in de jure sharing.

Due to this difference, incumbents in de jure and private negotiation could be expected to exhibit different behaviors. For example, when prompted to share spectrum by a higher authority, primary users should exhibit a tendency to maximize their interference protection measures since they cannot appropriate benefits from an increased probability of interference. This method of protection can emerge as they demand a clear and explicit definition of spectrum rights. Primary users, such as TV stations, microphone, radar and

\footnotetext{
${ }^{7}$ http://www.itu.int/ITU-D/ict/newslog/MVNO-Market-To-Double-In-FourYears-Driven-By-Emerging-Markets.aspx
} 
weather satellite systems make efforts in order to hold on to as many of the rights they enjoyed prior to the sharing mandate as possible. As an example, TV stations and microphone users are supported by a geolocation database that is designed to prevent secondary users from interfering with existing operations. Similarly, radar, weather satellite systems, and military transmitters request significant exclusion and protection zones. These actions illustrate the efforts of the incumbents to protect and guarantee the consistency of their services after their spectrum is offered for sharing. Incumbents appear to be aware that once spectrum is open for sharing it would be difficult (and costly) to regain the prior bundle of rights. If incumbents can benefit from sharing through negotiation, we would expect a tolerance for weaker rights definition and a willingness to rebundle and reassign rights.

In private negotiation, not only incumbents voluntarily share their spectrum but they may also receive a monetary compensation for this transaction. As Demsetz [9] writes, "A bundle of rights often attaches to a physical commodity or service, but it is the value of the rights that determines the value of what is exchanged." In private negotiation several situations may arise: for instance, primary users can require secondary users to follow a specific sharing etiquette; they may authorize secondary users to use the spectrum as desired under the license terms, or they can even transfer the de facto rights of spectrum usage to secondary users. Clearly, the (monetary) value of the spectrum lease will be directly proportional to the magnitude of the bundle of rights that the primary users are willing to grant to the spectrum entrants or secondary users.

2) Difference in applications and primary users: Applications and primary users also make a difference in spectrum usage. Let us start with de jure sharing in TVWS. TV stations provide fixed services with high transmission power, while microphone is mostly nomadic and unpredictable with low transmission power. In this case, TV signals are easier for secondary users to detect and predict. If the sensing capability of secondary users is required to be based on microphone signal detection, it will increase the operation cost for secondary users and, in consequence, decrease the spectrum utilization. However, if the sensing capability requirements are based on a TV signal detection floor, secondary users may interfere with microphone services. Current regulation requires microphone usage to register in a database in order to get protection.

In the case above, although incumbents have different services, all of them are civil services. In federal-commercial sharing bands, there are civil and military services. It is believed that military services are more critical and require higher privacy measures. In contrast, weather satellite communication is open to the public. Thus, the enforcement method will be particular to each case and will be discussed in Section V-B

In private negotiation, secondary users who obtain spectrum leases from spectrum trading have their own infrastructure, while MVNOs use, at least, primary users' access networks. In other words, primary users have more control over MVNOs' service than spectrum leasing through trading. Consequently, primary users may not have the incentive to enforce MVNO usage, but MVNOs may want to monitor the actual usage. In contrast, primary users may want to enforce the transmission parameters of cooperative secondary users to make sure that the contract agreements are met.

\section{ENFORCEMENT}

Demsetz [9] indicates that property rights determine how people may be benefited and harmed. They facilitate the coordination of actions across parties by specifying what usage rights and responsibilities different economic actors have with respect to goods and services exchanged in the economy. He further argues that enforcement is a key component of any property rights regime, since enforcement makes property rights more practical. Additionally, enforcement helps building trust among primary and secondary users. In this light, it is intuitive that the rearrangement of the bundles of rights that we presented in the previous sections will have an important influence on the deployment of enforcement techniques. In other words, enforcement techniques should adapt to new sharing situations and take into account the rights and obligations of the involved parties (i.e., primary and secondary users, spectrum sellers and buyers, users with the same rights to access unlicensed spectrum).

Our objective in this section is to analyze how enforcement may be carried out under different circumstances that arise when we consider various spectrum sharing scenarios. We will start with a brief description of the general aspects of enforcement and then delve into its key issues, which finally brings us to the specifics of enforcement in the spectrum sharing cases we have presented here.

\section{A. Spectrum Enforcement in General}

Shavell [29] points out three important aspects of an enforcement regime: (1) the timing of enforcement action (ex ante or ex post); (2) the form of enforcement sanctions; and (3) enforcement party.

Ex ante enforcement takes place before harmful events happen. The purpose of ex ante enforcement is to provide a prophylactic strategy for ensuring that unsafe technologies and processes, which may result in undesirable performance, are never applied. Mechanisms of ex ante enforcement include licensing, certification, beacon signals, database systems, exclusion and protection zones.

In contrast, ex post enforcement takes place after harmful action has already occurred. It can use different types of sanctions to deter harmful behavior, mainly via costs imposed on the guilty party. The most challenging mechanism for ex post enforcement is detection, which may use radio black boxes and sensor networks.

Ex post enforcement techniques typically involve some kind of adjudication and penalty. A monetary penalty is one type of sanction. However, this type of penalty might not be the most effective sanction in the spectrum sharing domain. Other ex post enforcement sanctions may include the revocation of licenses, fines, product recalls, or modifications to operating 
rights. Woyach and Sahai [30] discuss the termination of operation as an alternative sanction. It is evident that different types of sanctions depend on the types of applications, device limitations, detection methods, spectrum sharing mode, to mention a few factors. Every situation must be evaluated separately, as there is no universal sanction for all spectrum sharing cases.

Another question that arises is who performs detection, adjudication, etc. The options include voluntary (e.g. selfregulation, self-enforcement) or compulsory (e.g., enforced by third parties). Third parties might be regulatory authorities, administrative courts, or general courts. Market players such as primary users, secondary users, and spectrum brokers are other candidates for third parties. Moreover, power may be delegated to an industry enforcement bureau or agency. We can also find situations in which hybrid compliance approaches are applicable.

\section{B. Enforcement in different sharing scenarios}

In this section, we consider enforcement in the rights regimes that emerge from the sharing scenarios we discussed above. Included in this is a brief discussion about which entities conduct enforcement, enforcement distinctions for each right regime and enforcement techniques. It is clear that due to the spectrum rights rearrangement, enforcement goals, incentives and methods adjust accordingly.

1) Enforcement in exclusive use: In exclusive use, the real estate metaphor for spectrum is perhaps most apt. As discussed above, a spectrum license confers several rights, including the right to transmit and the right to receive without interference. Notably, traditional spectrum licenses often also limit the services that the license holder may provide.

In this scenario, license holders would seek to "patrol" the boundaries of their electrospace to ensure their right to receive without interference. Spectrum managers (i.e., regulators) may wish to "patrol" license holder behavior to ensure that the requirements (and limitations) of the license are being met.

If the enforcement is focussed on regulatory rules, such as license terms, the FCC has the statutory authority to resolve complaints such as interference, tower registration, equipment requirements, unauthorized construction or operation and compliance with operational provisions of licenses (http://transition.fcc.gov/eb/sed/).

License holders are also interested in enforcement, since their profits stem from providing services under the license terms. Hazlett [4] shows that private action in resolving interference complaints was significant in the early days of radio. To reduce the cost (and time) associated with complaint resolution, industry organizations have formed "frequency advisory committees" (FACs) to collect and manage interference complaints and, presumably, to attempt informal resolution ${ }^{8}$. In a similar fashion, CTIA has a website to collect and perform initial investigation on complaints related to the $800 \mathrm{MHz}$

\footnotetext{
${ }^{8}$ http://www.fcc.gov/guides/private-land-mobile-interference-complaints
}

public safety band ${ }^{9}$. In each case, the FCC provides the ultimate authority on interference complaints.

2) Enforcement in the spectrum commons: Nominally, enforcement is not a strong factor in the spectrum commons. There is, after all, no right to receive without interference, so "patrolling electrospace" does not make sense. But operations in the commons is not without rules (e.g., spectrum etiquette and power limits), so some enforcement may be appropriate. Indeed, the FCC may adjudicate matters that stem from equipment that does not comply with technical rules of shared bands.

More generally, Smith [2] argues that governance of commons could result in superior outcomes, so it is reasonable that this would emerge in spectrum commons as well. Ex ante measures of governance include explicit coordination of frequency use, the "acquisition" of rights through means such as ancillary rights (e.g., real estate), etc. Ex post governance actions can include dispute resolution (such as case described by Sandvig [8] and described above) and measures that are derived from ancillary rights (University administrators may require the removal of access points on non-rental spaces despite the FCC's OTARD rules.).

The institutional locus of this kind of governance is highly dependent on the particular form of commons, its situation and its governance. Governments can play a role (as shown in [8]), as can property owners. It is equally plausible that a self-governance system could emerge. An example of this is found in the amateur radio community. As discussed above, amateur radio enthusiasts have the right to build infrastructure, the right to transmit in amateur frequencies, if they have a license, and they have the right to receive (as do people without amateur licenses), but not the right to receive without interference. In this case, the Amateur Radio Relay League (ARRL) attempts to provide ex ante interference management through the National Frequency Coordinators' Council ${ }^{10}$. This group has been sanctioned by the FCC to perform management of amateur radio frequencies and they work with regional frequency coordinators to establish management guidelines and to perform initial ex post adjudication of interference reports.

3) Enforcement in spectrum sharing: In many senses, exclusive use and commons lie on opposing ends of a spectrum. Between these extremes lie spectrum sharing and commons with governance (briefly discussed in the previous section). While governance solutions may not involve the creation of enforceable rights, it can often mitigate some of the more serious negative aspects of commons. Since spectrum sharing implies a hierarchy of rights so questions of enforcement become more complex.

a) De jure sharing: Spectrum sharing can be mandated (de jure) or arrived at cooperatively (negotiated). In de jure sharing, primary users (license holders) must share, perhaps without explicit compensation. Since sharing is mandated, and

\footnotetext{
${ }^{9}$ http://www.publicsafety800mhzinterference.com/CTIAWeb/

${ }^{10}$ http://nfcc.us/
} 
since primary users may not profit from the sharing, one would expect them to be highly sensitive to interference of any kind. In terms of the rights framework described above, incumbents would seek to defend their right to receive without interference while yielding ground on the rights to transmit and to establish infrastructure.

An example of de jure spectrum sharing is described in [31]. The U.S. National Telecommunications and Information Administration (NTIA), which manages federal government spectrum in the U.S., has been asked to make spectrum available for commercial use. The NTIA has examined the 1695$1710 \mathrm{MHz}$ band, which is currently assigned to the National Oceanic and Atmospheric Administration's (NOAA's) Meterological Satelitte (MetSat) downlinks. Because the sharing was de jure, relocating the earth stations away from population areas (to maximize the benefits of sharing) was not accepted as a viable solution. In addition, initial ex ante measures included large "exclusion zones" that protected the incumbents but reduced the value to entrants; this was subsequently relaxed to somewhat less restrictive "protection zones". Enforcement, in this case, was biased very heavily toward ex ante measures, partly because the incumbents could not negotiate the terms of sharing and also because no viable ex post adjudication mechanism exists

b) Negotiated sharing: In negotiated sharing, secondary users may pay a spectrum leasing fee to obtain the right to operate on the (shared) spectrum and primary users may sacrifice some of their own services (or service quality) in order to get additional revenue from spectrum leasing fees. Consequently, a goal of enforcement in this case is the investment made by primary and secondary users. Secondary users need to make sure that primary users do not operate the same electrospace. Primary users may be interested in actual QoS level rather than secondary users transmission terms. In other words, it may not be a concern for primary users as long as their services are not harmed by secondary users. Similarly, spectrum entrants (secondary users) want to be sure that they are able to use the electrospace they bargained for.

Spectrum sharing may also be for underlay rights. For example, if the rights to interfere are determined as interference temperature, which allows secondary users to operate as long as the interference is under the interference temperature threshold, then the enforcement entity should measure the interference level and detect secondary users that violate the threshold. On the contrary, if the rights to interfere are determined by a spectrum leasing contract, both parties have the incentive to enforce and the basis for enforcement is the contract terms. In summary, entities that have the rights to control and rights to use the spectrum have incentives to enforce.

In negotiated sharing, the primary goal of enforcement for the primary and secondary users is to make contracts effective. Thus, both spectrum users have the incentive to monitor the actual usage, since both primary and secondary users have the incentive to violate spectrum leasing agreements in order to obtain higher QoS. Regulatory bodies also have an interest in enforcement, though they are likely to focus on the license terms; i.e., it is not a concern for the regulator as long as the license terms are not violated.

c) Locus of enforcement: While a regulator or governmental entity might be considered the principal enforcement agent, this solution does not seem to fit the negotiated sharing scenario well. Bi-lateral mechanisms could be used to enforce sharing agreements, though this does not scale particularly well. Instead, one could imagine that third parties, such as database providers and sensor network providers [32], might offer enforcement services. Third party enforcement institutions must be perceived as independent (for fairness) and efficient if they are to emerge as a viable alternative.

\section{Summary}

Enforcement of rights in spectrum poses challenges as the rights bundles change and become more complex. In this section, we constructed a relationship between a changing rights environment and the requirements of an enforcement environment. This is necessary because, as pointed out by Demsetz [9], rights are meaningless without enforcement. This section is necessarily incomplete, since particular enforcement approaches are highly situation-specific [27].

\section{Conclunsions And Consequences}

As De Vries mentioned in [19], "conflict between operators is due, in large part, to poorly defined rights, particularly across boundaries between different service types." In this paper, we do not design spectrum rights, instead, we argue that spectrum usage is actually determined by a bundle of rights rather than just spectrum related rights. As an example, in the ISM bands where all users have the rights to access the spectrum, whether they can establish infrastructure and provide services depends on whether they have the rights to use the land or not. Further, we show that spectrum sharing involves a re-arrangement of rights bundles across various stakeholders.

In this paper, we have proposed candidates that can be included in the bundle of rights: rights to transmit and receive, rights to receive without interference, rights to interfere, rights to operate a specific service, spectrum usage right, spectrum management right, underlay right, overlay right, etc. Additionally, we present more detailed rights that arise when we consider specific situations and conflict-solving in spectrum sharing. What we aimed to illustrate by providing a finergrained list of rights, is that the original bundle of rights that was attached to the spectrum license has been "broken" and further rearranged into more complex and specific bundles as a consequence of the emergence of different models of spectrum sharing.

As we could expect, this restructuring of the bundle of rights is not an isolated factor; it has a significant influence on spectrum users' behavior, spectrum trading and on enforcement. Demsetz [9] indicates that enforcement is a key component of the property rights regime, since it makes property rights more practical. In other words, before enforcement occurs, parties must have a clear notion of the types of rights they own. 
Those rights might not be defined as precisely as it would be desirable, but they surely need to be enforceable. From the enforcement case studies that we have presented in this work, it is clear that different rights affect users' incentives for performing enforcement and they are further related to the benefit each party can obtain from developing the enforcement activities. For instance, we have seen that in cases where spectrum sharing is mandated, primary users have a higher incentive to preserve their (higher priority) rights and perform enforcement activities than secondary users; however, as the latter get more financially involved in obtaining spectrum (i.e., private negotiation) the incentives for taking part in enforcement activities arise as there is a need to claim rights that are appropriate to the level of investments incurred ${ }^{11}$.

After examining how bundles of rights vary under spectrum sharing schemes, we are able to briefly examine some enforcement questions for each particular spectrum sharing case. There are situations that appear to have similar enforcement approaches; however, the characteristics of the parties involved in the spectrum sharing models call for nuances that differentiate one enforcement procedure from another. Thus, our conclusion is consistent with [27], in that enforcement of spectrum sharing is highly situation-specific. While this conclusion is somewhat generic, it is nonetheless satisfying that the empirical approach of the previous papers are consistent with the theoretical approach developed.

\section{ACKNOWLEDGMENTS}

This work was supported in part by the U.S. National Science Foundation under Grant 1149422. The authors would like to thank J.P. DeVries for his insightful comments on an earlier draft.

\section{REFERENCES}

[1] M. B. Weiss, W. H. Lehr, L. Cui, and M. Altamaimi, "Enforcement in dynamic spectrum access systems," in Telecommunications Policy Research Conference. Telecommunications Policy Research Conference, September 2012. [Online]. Available: http://d-scholarship.pitt.edu/13609/

[2] H. E. Smith, "Exclusion versus governance: Two strategies for delineating property rights," The Journal of Legal Studies, vol. 31, no. S2, pp. S453-S487, June 2002.

[3] J. P. De Vries, "De-situating spectrum: Rethinking radio policy using non-spatial metaphors," in New Frontiers in Dynamic Spectrum Access Networks, 2008. DySPAN 2008. 3rd IEEE Symposium on, 2008, pp. $1-$ 17.

[4] T. W. Hazlett, "The rationality of usiregulation of the broadcast spectrum," The Journal of Law and Economics, vol. XXXIII, no. 1, pp. 133-175, April 1990.

[5] M. B. Weiss and W. H. Lehr, "Market based approaches for dynamic spectrum assignment," Working Paper http://dscholarship.pitt.edu/2824/, 2009.

[6] J. Peha, "Sharing spectrum through spectrum policy reform and cognitive radio," Proceedings of the IEEE, vol. 97, no. 4, 2009.

[7] C. Sandvig, "The return of the broadcast war," in Telecommunications Policy Research Conference, 2005.

[8] _ _ "Spectrum miscreants, vigilantes, and kangaroo courts: The return of the wireless wars," Federal Communications Law Journal, vol. 63, no. 2 , pp. 483-499, 2011

${ }^{11}$ We base our analysis of rights on the liberal social theory adopted by Demsetz. It should be pointed out that, in the context of alternative social/critical theories, different rights and arrangements may obtain.
[9] H. Demsetz, "Toward a theory of property rights," American Economic Review, vol. 57, no. 3, pp. 347-359, 1967.

[10] R. H. Coase, "The problem of social cost," Journal of Law and Economics, pp. 1-44, October 1960

[11] _ - "The federal communications commission," Journal of Law and Economics, vol. 2, no. ArticleType: research-article / Full publication date: Oct., 1959 / Copyright 1959 The University of Chicago, pp. 140, 1959.

[12] W. L. Fishman, "Property rights, reliance, and retroactivity under the communications act of 1934," Fed. Comm. LJ, vol. 50, p. 1, 1997.

[13] G. R. Faulhaber and D. J. Farber, Rethinking rights and regulations: institutional responses to new communication technologies. MIT Press, 2003, ch. Spectrum management: Property rights, markets, and the commons, pp. 193-226.

[14] A. S. De Vany, R. D. Eckert, C. J. Meyers, D. J. O'Hara, and R. C. Scott, "A property system for market allocation of the electromagnetic spectrum: A legal-economic-engineering study," Stanford Law Review, pp. 1499-1561, 1969

[15] R. Matheson and A. C. Morris, "The technical basis for spectrum rights: Policies to enhance market efficiency," Telecommunications Policy, vol. 36, no. 9, pp. $783-792,2012$.

[16] R. P. Margie, "Can you hear me now? getting better reception from the FCC's spectrum policy," Stanford Law Review, vol. 5, 2003.

[17] T. Forde and L. Doyle, "Cellular clouds," Telecommunications Policy, vol. 37, no. 23, pp. $194-207,2013$.

[18] J. Panchal, R. Yates, and M. Buddhikot, "Mobile network resource sharing options: Performance comparisons," Wireless Communications, IEEE Transactions on, vol. 12, no. 9, pp. 4470-4482, 2013.

[19] J. De Vries and K. Sieh, "The three Ps: Increasing concurrent operation by unambiguously defining and delegating radio rights," in New Frontiers in Dynamic Spectrum Access Networks (DySPAN), 2011 IEEE Symposium on, 2011, pp. 56-70.

[20] M. B. Weiss and L. Cui, "Spectrum trading with interference rights," in International Conference on Cognitive Radio Oriented Wireless Networks (CROWNCOM), 2012.

[21] M. Cave and P. Webb, "The unfinished history of usage rights for spectrum," in New Frontiers in Dynamic Spectrum Access Networks (DySPAN), 2011 IEEE Symposium on, 2011, pp. 41-46.

[22] D. P. Satapathy and J. M. Peha, Interconnection and the Internet: Selected Papers from the 1996 Telecommunications Policy Research Conference. Lawrence Erlbaum Associates, 1997, ch. Spectrum Sharing Without Licenses: Opportunities and Dangers.

[23] FCC, "Commission staff clarifies fccs role regarding radio interference matters and its rules governing customer antennas and other unlicensed equipment," Federal Communications Commission, dA 04-1844.

[24] — "Petition of continental airlines, inc. for a declaratory ruling," Federal Communications Commission, eT 05-247.

[25] — "In the matter of continental airlines petition for declaratory ruling regarding the over-the-air reception devices (OTARD) rules," Federal Communications Commission, fCC 06-157.

[26] O. E. Williamson, Markets and Hierarchies. New York: Free Press, 1975.

[27] M. Altamimi, M. B. Weiss, and M. McHenry, "Enforcement and spectrum sharing: Case studies of federal-commercial sharing," in Telecommunications Policy Research Conference, September 2013. [Online]. Available: http://d-scholarship.pitt.edu/19666/

[28] B. P. Freyens and M. Loney, "Emerging issues in white space regulation," Telecommunications Policy, vol. 37, no. 2-3, pp. 208 - 218, 2013.

[29] S. Shavell, "The optimal structure of law enforcement," Journal of Law and Economics, vol. 36, no. 1, pp. 255-287, 1993.

[30] K. Woyach and A. Sahai, "Why the caged cognitive radio sings," in New Frontiers in Dynamic Spectrum Access Networks (DySPAN), 2011 IEEE Symposium on, 2011, pp. 431-442.

[31] M. B. Weiss, M. Altamaimi, and M. McHenry, "Enforcement and spectrum sharing: A case study of the $1695-1710 \mathrm{mhz}$ band," in 8th International Conference on Cognitive Radio Oriented Wireless Networks (CrownCom), July 2013. [Online]. Available: http://d-scholarship.pitt.edu/18619/

[32] M. B. Weiss, S. Delaere, and W. H. Lehr, "Sensing as a service: An exploration into the practical implementation of DSA," in IEEE DySPAN, 2010 